DOI 10.37882/2223-2982.2020.05-2.21

\title{
ФОРМИРОВАНИЕ НОРМАТИВНО-ПРАВОВОЙ БАЗЫ ПРОИЗВОДСТВЕННОЙ КООПЕРАЦИИ В СССР В 1986 - ПЕРВОЙ ПОЛОВИНЕ 1988 ГОДАХ
}

\section{THE FORMING OF COOPERATION'S LEGISLATION IN THE USSR IN 1986 - FIRST HALF OF 1988}

A. Chudetckii

Summary: Cooperatives were remarkable innovation in the Soviet economy of the second half of 1980 s and had a great role in the transition to the market economy. Authorities had to form the cooperative's legislation. The article attempts to consider the process of cooperation's legislation forming in1986 - first half of 1988 as a sequential process from the "experiment" to the new law "About the cooperation in the USSR" in 1988.

Keywords: deficit, cooperatives, cooperation, Perestroika, consumer market.

\author{
Чудецкий Александр Николаевич \\ Aспирант, ФГБУН «Санкт-Петербургский институт \\ истории» Российской академии наук \\ 0000000025@mail.ru
}

Аннотация: Производственные кооперативы - заметное нововведение в хозяйстве СССР второй половины 1980-х гг., сыгравшее большую роль при переходе к рыночной экономике. Перед властями стояла задача разработки комплекса нормативно-правовых актов для регламентации их деятельности. В статье предлагается рассматривать формирование нормативноправовой системы кооперации в СССР в 1986 - первой половине 1988 гг. как процесс, осуществлявшийся несколькими последовательными шагами от «эксперимента» до принятия закона «0 кооперации в СССР».

Ключевые слова: дефицит, кооперативы, кооперация, Перестройка, потребительский рынок.
B о второй половине 1980-х гг. в экономике СССР происходило расширение негосударственного сектора: предпосылкой этому стала необходимость насыщения потребительского рынка товарами и услугами, а как следствие поощрения мелкосерийного производства, способного гибко реагировать на спрос [11; с. 30]. В кооперации власть увидела один из инструментов организации такого производства.

При изучении развития кооперативов многие исследователи традиционно акцентировали внимание на законе «О кооперации в СССР» 1988 г., часто игнорируя постановления 1986 - 1987 гг. по этому же вопросу [13, 26] или лишь кратко их упоминая $[24,6,5]$. Такой подход позволил оценить роль этого закона в перспективе дальнейшего экономического развития страны, формирования основ частного предпринимательства и соответствующей отрасли права, однако его следствием стало занижение роли более ранних правовых актов, невозможность объяснить отдельные аспекты развития кооперации. Например, доктор экономических наук А.А. Бессолицын указывал, что «в начале 1988 года на 90\% всех кооперативных предприятий приходилось всего четыре типа кооперативов» [1, с. 67-68], однако отсутствие указания на постановления 1986 -v1987 гг. не позволило ему связать эти данные с системой права того времени [1].

Ряд других исследователей $[25,11]$ справедливо от- мечали, что после издания постановлений 1986 - 1987 гг. «кооперация, правда, со значительными трудностями, развивалась...» [25, с. 396]. Кандидат политических наук Е.В. Тышта указывала, что в феврале 1987 г. «Совет министров СССР разработал» нормативную базудля «кооперативов по производству товаров народного потребления, кооперативов по бытовому обслуживанию населения, и создания кооперативов общественного питания» [27, с. 211]. Она отметила, что постановления предполагали создание кооперативов при предприятиях, организациях или исполкомах по инициативе граждан и с согласия местного исполкома с правом найма рабочей силы и получения кредитов Госбанка СССР. Ключевыми принципами их работы автор статьи назвала самоокупаемость и самофинансирование, самостоятельное планирование производства и оплаты труда, свободное ценообразование [27, с. 211-212].

Вместе с тем, анализ постановления «Об организации заготовки и переработки вторичного сырья на кооперативной основе» от 14 августа 1986 г. показывает, что большая часть этих принципов, предусматривавших широкую свободу кооперативов в вопросах производства, планирования, ценообразования, оплаты труда, была сформулирована властью еще в этом документе [23, с.241-246]. В том числе, закреплялась связь нового типа предприятий с потребительским рынком путем их ориентации на производство товаров народного потребления [23, с. 241]. Очевидные параллели с постановле- 
ниями 1987 г. обнаруживаются в утвержденной системе налогообложения кооперативов и налоговых льгот (на первые два года работы), в функциях органа управления, при котором они создавались (снабжение сырьем, материалами, помещениями). Уже постановлением 1986 г. за исполкомами закреплялись функции регистрации кооператива (с указанием срока регистрации в 20 дней) [23, с. 241-246]. Это свидетельствует, что главные принципы работа кооперации были сформулированы еще в 1986 г. и использовались при разработке постановлений 1987 г.

Таким образом, начальной точкой в развитии нормативно-правовой базы кооперативного сектора на потребительском рынке, на наш взгляд, стоит считать появление постановления по вопросу кооперативов по заготовке и переработке вторичного сырья в 1986 г. Мы предполагаем, что формирование системы нормативноправовых актов, регламентировавших их деятельность, стало плацдармом для развития более широкой системы постановлений и подзаконных актов по вопросам кооперации.

Мы соглашаемся с кандидатом исторических наук С.А. Власовым, который, анализируя реформы Перестройки на Дальнем Востоке, отметил, что первые кооперативы появились «по инициативе сверху» [2, с. 100-106]. Предполагаем, что их создание в сфере переработки вторичного сырья в 1986 г. рассматривалось в качестве эксперимента «сверху» по развитию кооперации в целом. Об этом свидетельствует то, что постановление от 14 сентября 1986 г., будучи принятым Советом Министров СССР, не носило общесоюзный характер: его действие распространялось на территорию России, Белоруссии, Азербайджана, Прибалтийских республик [23, с. 241242]. Об «экспериментальном» характере кооперативов, осторожном и административном подходе к их организации в 1986 г. свидетельствуют указания Госснаба СССР В утвержденной им 18 сентября 1986 г. инструкции [9]: следовало «определить города и районы, где целесообразно организовать кооперативы», ориентироваться на рекомендуемое количество «по 8 - 10 кооперативов», определить «территории, где кооперативы будут осуществлять заготовительную деятельность с тем, чтобы не возникло дублирования с работой действующих организаций» [9, с. 116-117]. О планах по созданию первых кооперативов «сверху» говорит перечень функций территориальных органов Госснаба, среди которых - право «по согласованию с местными партийными и советскими органами» рекомендовать кандидатуру председателя кооператива и «создавать условия» для организационного собрания его членов [9, с. 116-117]. Вероятно, власти рассматривали возможность включения кооперативного производства в структуру плановой экономики: инструкция содержала указание «учитывать показатели планов развития кооперативов при формировании ... планов...» $[9$, с. 118].
Сбор информации для оценки возможности организации кооперативов должен был осуществляться согласно постановлению Государственного комитета СССР по материально-техническому снабжению от 5 сентября 1986 г. «Об организации заготовки и переработки вторичного сырья на кооперативной основе». Власти Белоруссии, Азербайджана, Латвии, Армении, Эстонии, Якутии и Волгоградской области (здесь мы вновь видим территориальные ограничения) должны были предоставить органам Госснаба информацию о возможности передачи имущества «для организации кооперативов», продажи им вторичного сырья и отходов производства $[22$, с. 115$]$.

Е.В. Тышта, ссылаясь на постановление Совета Министров СССР от 5 февраля 1987 г. «О создании кооперативов по производству товаров народного потребления», справедливо отметила, что цель властей в 1987 г. «была весьма рыночная: «...более полное удовлетворение потребностей населения в товарах народного потребления и развитие инициативы граждан» [27, с. 211]. Однако, как мы уже указывали, кооперативы в сфере вторсырья тоже планировалось связать с потребительским рынком: они должны были аккумулировать отходы и вторичное сырье «в первую очередь [образующиеся] у населения», а также сосредоточиться на «выпуске из него товаров народного потребления» [23, с. 241].

Изданные 5 февраля 1987 г. постановления «О создании кооперативов общественного питания» [18], «О создании кооперативов по бытовому обслуживанию населения» [19], «О создании кооперативов по производству товаров народного потребления» [21], а также 10 сентября 1987 г. «О создании кооперативов по выработке кондитерских и хлебобулочных изделий» [20] написаны по образцу постановления от 14 августа 1986 г. Вместе с тем, анализ опыта реализации постановления о создании кооперативов в сфере вторичного сырья привел к тому, что были облегчены условия регистрации и работы кооперативных предприятий. Новые постановления получили общесоюзный характер, снизился возрастной ценз для кооператоров до 16 лет [18, 19, 21], понизились ставки налогообложения [18, 19, 20, 21], исключено указание, что наем допустим, если «среди членов кооператива нет соответствующих специалистов или ... предусмотренные ... работы не могут быть выполнены в необходимые сроки силами членов кооператива» [23, с. 247].

Возможность расширения кооперативного сектора за пределы сферы вторичного сырья была предусмотрена еще законом от 19 ноября 1986 г. «Об индивидуальной трудовой деятельности» [8], согласно которому «государство поощряет объединение этих [занимающихся индивидуальной трудовой деятельностью] граждан в установленном законодательством порядке в кооперативы...» [8, с. 906], однако в нем не были описаны 
особенности такого объединения. В условиях правовой неопределенности местные власти предпочитали избегать вопросов кооперации: например, лишь одно напрямую связанное с нею распоряжение было опубликовано в Бюллетене Исполнительного комитета Ленинграда за 1986-1987. О недостаточном понимании местным чиновничеством статуса кооперативов свидетельствует содержание распоряжения Исполкома Ленсовета от 2 февраля 1987 года «О подготовительной работе по организации и развитию индивидуальной трудовой деятельности и кооперативов в Ленинграде» [32]. И в проекте, и в конечном тексте распоряжения мы находим фразу о развитии «индивидуальной трудовой деятельности кооперативов и граждан в Ленинграде» [32, л. 159, 163], что говорит о неверном восприятии кооперативов в качестве разновидности индивидуальной трудовой деятельности.

Постановления от 5 февраля 1987 г. определяли приоритетные направления развития кооперативов и конкретные правовые основы их функционирования. Их появление заставило местные власти отреагировать изданием местных нормативно-правовых актов. Исполком Ленсовета в распоряжении от 6 апреля 1987 г. «О мерах по созданию кооперативов в Ленинграде» подал указаниями формального характера («донести до сведения...», «принять неотложные меры...») сигнал о понимании необходимости развития кооперации [33, л. 186-187], В проекте распоряжения говорится о существовании в Ленинграде 18 кооперативов, а в утвержденном тексте - о 42 кооперативах [33, л. 186, 192-193]. Возможно, ленинградские власти задержали издание этого распоряжения (более, чем на месяц после общесоюзных постановлений), чтобы показать более внушительные результаты работы.

Издание серии общесоюзных постановлений о развитии кооперативов в начале 1987 г. свидетельствует, что власть учла опыт «эксперимента» в сфере вторичного сырья и поставила цель формирования большой сети кооперативов на потребительском рынке. Совет Министров прекратил «экспериментальное» положение кооперативов в сфере заготовки и переработки вторичного сырья постановлением от 3 апреля 1987 г. «Вопросы кооперативов по заготовке и переработке вторичного сырья» [4]. Они уравнивались с другими кооперативами в налогообложении, условиях кредитования, социального обеспечения, возможности найма рабочих [4, с.547-549].

Весной - летом 1987 г. встала задача легитимации положения кооперации, стимулирования местных властей на создание условий для ее развития. Серия постановлений 1987 г. содержала призывы к отраслевым ведомствам и местным властям всецело способствовать развитию кооперативного сектора $[16,17]$. Дублирование этого указания было сигналом, что развитие коопе- рации следовало рассматривать как одно из генеральных направлений экономической реформы. Исполком Ленсовета отреагировал на него решением от 30 ноября 1987 г. «О дальнейшем развитии индивидуальной трудовой деятельности и создании кооперативов»: как свершившийся факт констатировалось, что местные власти «проводят организаторскую работу по расширению сети кооперативов», хотя решения в основном включали формальные поручения по форме «обратить внимание...», «направить работу...», «требовать...» [15, с. 2-3].

Формирование местной системы управления новым сектором экономики свидетельствует о постепенной легитимации кооперации в глазах местного чиновничества. В Ленинграде районным исполкомам отдавались функции регистрации и ликвидации кооперативов, сбора информации об их развитии и ее ежемесячного предоставления городскому исполкому [15, с. 4]. Для создания условий развития кооперативных предприятий учреждались временные органы управления. В 1987 г. были учреждены специальная рабочая группа при Главном управлении торговли города для организации сотрудничества кооперативов с государственными предприятиями и совместная комиссия исполкомов Ленсовета и Леноблсовета по совершенствованию налогообложения кооперации [3].

Помимо временных формировалась система постоянно работавших специализированных органов управления. В Ленинграде весной 1987 г. были учреждены городская и районные комиссии по работе с кооперативами [10]. К декабрю 1987 г. [15, с. 2-3] при исполнительном комитете Ленинградского городского совета был создан сектор кооперативной и индивидуальной трудовой деятельности [19, Л. 94] (вероятно, в основу легла созданная ранее комиссия по индивидуальной трудовой деятельности [32, л. 160]). Во главе районных комиссий, как правило, находились заместители председателей исполкомов районов [15, с. 2-3]: вероятно, благодаря этому вопросы регистрации кооперативов, формально оставаясь задачей исполкомов, фактически передавались в руки отдельной комиссии.

Кроме вертикальной модели управления реализовывалась модель отраслевой системы руководства кооперативным сектором экономики. В 1987 г. решением Исполкома Ленсовета от 30 ноября надзор за кооперативами был делегирован отраслевым управлениям: начальнику Управления бытового обслуживания Ю.П. Филатову, начальнику Главного управления общественного питания А.А. Томашевичу, начальнику Жилищного управления М.Ф. Петруку, начальнику Управления предприятиями коммунального обслуживания В.В. Морозову и т.д. [14].

Следствием правотворческой деятельности властей 
и появления системы специальных органов управления стало расширение роли кооперации в экономике. К июлю 1987 г. насчитывалось 9124 кооперативов в стране: большинство из них занимались производством товаров народного потребления, оказанием бытовых услуг и услуг общественного питания [11, с. 31]. В Ленинграде на 1 июля 1987 г. было зарегистрировано 235 кооперативов [28, л. 1], на 1 апреля 1988 г. - 704 [28, л. 94], на 1 июля 1988 г. - 1453 [30, л. 9, 15-18].

В литературе отмечалось, что развитию кооперации препятствовали бюрократические препоны: местные власти часто «сознательно создавали кооперативам административные барьеры, либо считали их неперспективным в борьбе с товарным дефицитом» [2, с.102]. Из-за этого в СССР в начале 1988 г. только 60\% зарегистрированных кооперативов начали работать [12, с. 143]. Мы находим подтверждение данным фактам на местном уровне. В Ленинграде горисполком в 1987 г. отметил недостатки в работе местных органов власти: нарушения 20-дневного срока регистрации, бюрократические проволочки, проблемы снабжения сырьем и материалами. Доля зарегистрированных, но не работавших кооперативов в Ленинграде росла: если на 1 июля 1987 г. их насчитывалось 68 (28,9 \%) [28, л. 1], то на 1 апреля 1988 г. - уже 318 (45\%) [29, л. 94], на 1 июля 1988 г. - 739 (51\%) [30, л. 9, 15-18]. К концу 1988 г. число таких кооперативов Ленинграда по сравнению с первым кварталом года выросло в 5 раз: темпы роста их числа в городе и области превышали темпы роста числа кооперативов в целом [31, л. 1-5].

Необходимость более детальной регламентации деятельности кооперативов в связи с расширением и услож- нением их сети, наличием трудностей и препятствий на пути их развития стала ключевой предпосылкой к принятию 26 мая 1988 г. закона «О кооперации в СССР». Мы соглашаемся с авторами, которые указывали, что данный закон стал «результатом развития кооперативного законодательства» [25, с. 398]. Он содержал указание на принципы функционирования производственной кооперации, утвержденные постановлениями 1986 - 1987 гг., а также претендовал на регулирование потребительской кооперации, деятельности колхозов и совхозов. Появившаяся возможность организации кооперативов в любом легальном виде деятельности [7] обозначила переход к новому периоду в истории развития этого сектора экономики, когда за кооперативами окончательно утвердились права самостоятельных производственных объединений.

Таким образом, начало формирования нормативноправовой базы производственной кооперации на потребительском рынке следует отнести к сентябрю 1986 г., когда было утверждено положение «Об организации заготовки и переработки вторичного сырья на кооперативной основе». В 1987 г. серией правовых актов Совет Министров СССР укрепил положение кооперации в экономической системе страны, дал властный сигнал местным управленцам о необходимости ее развития, указал на приоритетные направления в формировании нового сектора экономики. Правотворческая деятельность 1987 - первой половины 1988 гг. стала стимулом для роста числа кооперативов, однако не решала многие проблемы, связанные с их непосредственным функционированием: пути решения этих проблем должны были быть предложены законом 1988 года «О кооперации в CCCP».

\section{ЛИТЕРАТУРА}

1. Бессолицын А.А. Предпринимательство в СССР // Вопросы новой экономики. - 2010. - № 3 (15). - С. 59-70.

2. Власов С.А. Развитие кооперативов и их роль в борьбе с товарным дефицитом на Дальнем Востоке в годы перестройки // Гуманитарные исследования в Восточной Сибири и на Дальнем Востоке. - 2016. - № 1 (35). - С. 100-106.

3. Вниманию кооперативов и лиц, занимающихся индивидуальной трудовой деятельностью! // Вечерний Ленинград. - 1987, 3 октября. - № 226.

4. Вопросы кооперативов по заготовке и переработке вторичного сырья // Собрание постановлений Правительства СССР. - 1987. - № 26. - Ст. 90. С. 547550.

5. Гошуляк В.В. Эволюция социально-экономических основ конституционного строя в годы перестройки // Юридическая наука в Китае и России. - 2017. № 1. - C. 59-93.

6. Есина Ю.Л., Воротынцева С.А. Законодательство для малого бизнеса: ретроспективный анализ. Особенности формирования правового поля государственной поддержки малого предпринимательства в России // Российское предпринимательство. - 2011. - № 1-1. - С. 16-23.

7. Закон «0 кооперации в СССР» // Ведомости Верховного Совета СССР. - 1988. - № 22. - Ст. 355. С. 375-421.

8. Закон ССС «0б индивидуальной трудовой деятельности» // Ведомости Верховного Совета СССР. - 1986. - № 47. - Ст. 964. С. 905-914.

9. Инструкции для Госснабов союзных республик, главных территориальных управлений Госснаба СССР по созданию и развитию деятельности кооперативов по заготовке и переработке вторичного сырья. Утверждена Госснабом СССР 18 сентября 1986 года № 082-178-4623 // Вторичные ресурсы. Сборник нормативных актов. - М.: Юридическая литература, 1988. - С. 116-118.

10. Как получить патент. // Вечерний Ленинград. - 1987, 30 марта. - № 74.

11. Кирсанов Р.Г. Развитие кооперативного сектора в период перестройки и его роль в стабилизации потребительского рынка в СССР. // Вестник Волгоград- 
ского государственного университета. Серия 4. История. - 2014. - № 4 (28). - C. 30-36. - D0I:10.15688/jvolsu4.2014.4.4.

12. Кооперация - важной направление стратегии обновления (за «круглым столом» Института экономики АН СССР и журнала «Вопросы экономики») // Вопросы экономики. - 1988. - № 6. - С. 141-152.

13. Левшук М.В. К вопросу правового регулирования деятельности кооперативов в Советский период (историко-правовой аспект) // Роль высшего образования в развитии кооперации. Материалы международной научно-практической конференции профессорско-преподавательского состава и аспирантов. 5 февраля 2016 года. - Белгород: Издательство БУКЭП, 2016. - С. 152-161.

14. 0 дальнейшем развитии индивидуальной трудовой деятельности и создании кооперативов. Решение Исполкома Ленсовета от 20 ноября 1987 года // Вечерний Ленинград. - 1987, 25 декабря. - № 295.

15. 0 дальнейшем развитии индивидуальной трудовой деятельности и создании кооперативов. 30 ноября 1987 года. № 953 // Бюллетень Исполнительного комитета Ленинградского совета народных депутатов. - 1988. - № 4. - С. 2-5.

16. 0 перестройке деятельности министерств и ведомств сферы материального производства в новых условиях хозяйствования // Собрание постановлений Правительства СССР. - 1987. - № 38. - Ст. 122. С. 795-809.

17. 0 совершенствовании деятельности республиканских органов управления // Собрание постановлений Правительства СССР. - 1987. - № 39. - Ст. 124. С. 827-850.

18. 0 создании кооперативов общественного питания // Собрание постановлений Правительства СССР. - 1987. - № 10. - Ст. 41. С. 195-208.

19. 0 создании кооперативов по бытовому обслуживанию населения // Собрание постановлений Правительства СССР. - 1987. - № 11. - Ст. 43. С. 227-241.

20. 0 создании кооперативов по выработке кондитерских и хлебобулочных изделий // Собрание постановлений Правительства СССР. - 1987. - № 44. - Ст. 148. С. $930-944$.

21. 0 создании кооперативов по производству товаров народного потребления // Собрание постановлений Правительства СССР. - 1987. - № 10. - Ст. 42. С. 208-222.

22. 06 организации заготовки и переработки вторичного сырья на кооперативной основе. Постановление Госснаба СССР от 5 сентября 1986 г. № 123 // Вторичные ресурсы. Сборник нормативных актов. - М., Юридическая литература, 1988. - С. 115.

23. 06 организации заготовки и переработки вторичного сырья на кооперативной основе // Собрание постановлений Правительства СССР. - 1987. - 1987. № $11-$ С. 44. С. 241-255.

24. Семенченко А.Б. Законодательное регулирование кооперации как принципиальной новой формы хозяйствования во второй половине 1980-х гг., и ее значение в либерализации экономических отношений в СССР // 0бщество и право. - 2011. - № 5. - С. 39-42.

25. Смирнов А.С. Становление и развитие законодательства, регулирующего право собственности производственных кооперативов // Научно-технический вестник Санкт-Петербургского государственного университета информационных технологий, механики и оптики. - 2006. - № 24. - С. 394-403.

26. Тычинин С.В. Развитие законодательства о кооперации в СССР и России в период с 1929 по 1996 г. // История государства и права. - 2004. - № 3. - С. 40-43.

27. Тышта Е.В. Создание нормативно-правовой основы деятельности кооперативов в СССР (1987 - 1989 гг.) // Вестник Кемеровского государственного университета. - 2015. - № 2-6 (62). - С. 210-214.

28. ЦГА ИПД СПб - Центральный государственный архив историко-политических документов Санкт-Петербурга Ф. 25 0п. 169. Д. 89.

29. ЦГА ИПД СПб. Ф. 25. ОП. 169. Д. 173.

30. ЦГА ИПД СПб. Ф. 24. Оп. 249 Д. 171.

31. ЦГА СПб - Центральный государственный архив Санкт-Петербурга. Ф. 1684. Оп. 15. Д. 515.

32. ЦГА ППб. Ф. 7384 ОП. 58 Д. 247.

33. ЦГА СПб. Ф. 7384. 0п. 58. Д. 259. Л. 186-191.

(c) Чудецкий Александр Николаевич (0000000025@mail.ru).

Журнал «Современная наука: актуальные проблемы теории и практики» 